\title{
Prevalence of Drop out and associated factors in Measles immunization among children in Kanyakumari District, Tamilnadu, India.
}

\author{
Article by Alber M Mathiarasu ${ }^{1}$, Pethuru Devadason ${ }^{2}$, Usha Devi Karunakaran. ${ }^{3}$ \\ ${ }^{1}$ Associate Professor, Department of Community Medicine, Kanyakumari Government \\ Medical College, Asaripallam, Tamilnadu, India. \\ ${ }^{2}$ Professor, Department of Community Medicine, SMIMS, Kulasekharam, Tamilnadu, \\ India. \\ ${ }^{3}$ Professor and Head, Department of Community Medicine, SMIMS, Kulasekharam, \\ Tamilnadu, India. \\ Email: drpethuru@rediffmail.com
}

\begin{abstract}
Introduction: Measles is the main cause of childhood morbidity and mortality and highly prevalent worldwide. Over the last 15 years there has been a general decline in all the reported Vaccine Preventable Diseases in India but the decline in measles incidence is far below the expected level. WHO targets measles next to polio for eradication.

Objectives: 1) To determine the immunization coverage in measles in Kanyakumari district and 2) To identify the factors associated with Drop outs.

Methodology: This is a community based cross sectional study conducted in whole Kanyakumari district in Tamilnadu, India from June 2012 to May 2013 with 210 children in the age group between 12 and 23 completed months selected by $30 \times 7$ cluster sampling method. Structured pre tested Questionnaire was used to collect data.

Results: Mean age of the children was $18.1 \pm 3.1$ (SD) months. Out of 210 children, 171 children (81.4\%) were immunized for measles vaccination. $64.9 \%$ vaccinated in Government facility and $35.1 \%$ of children in private setup. Forgetfulness due to longer timegap between OPV/DPT $3^{\text {rd }}$ Dose and Measles vaccine was the most common factor for drop out constituting 25.6\%. Area of Residence, Marital Status of the parents, Total Income, Distance and the Availability of Immunisation card are the significantly associated with Dropouts.

Conclusion: The prevalence of dropout is 18.6\%. Forgetfulness, Area of residence, Marital status and Income of parents, Distance, Availability of immunization card were the significant factors associated with Drop outs.
\end{abstract}

Keywords: Immunization Coverage, Measles, Drop out, Vaccination.

\section{Introduction}

Measles, an acute viral exanthematous fever is the most important cause of childhood mortality and morbidity in developing countries (Akhalesh KS, 2012). Globally every year, measles was responsible for approximately six million deaths of infants and children before the development of safe and effective vaccines. Beginning in 1963, the availability and increasing use of live attenuated measles vaccines have made prevention possible. Despite these however an estimated 20 million cases of measles resulted in 2,42,000 deaths in 2006 (WHO, 2014). Approximately 1,22,000 children under the age of five years died from measles in 2012 globally. In India, measles had 84 outbreaks in 2014 leading to 5,248 cases. According to WHO estimates, measles is responsible for about 4 percent of under -five mortality in India (NRHM, 2014).

Measles is often considered to be an unimportant infection. But it is leading cause of childhood mortality \& morbidity in developing countries (Surender NG, 2009). It is not a killer disease as such. But it leads to many complications which are life threatening. After introduction in UIP, outbreaks occurred once in 5 years and the number of reported cases has 
South American Journal of Public Health

Special Edition May 2016

declined from 1,62,560 in 1989 to 29,339 cases in 2011. Between 1984 and 2013 the infant mortality rate (IMR) in India also has fallen from 104 to 42 per 1000 live births (Rajesh Vaidhya, 2009).

The rapid increase in measles immunization coverage levels has saved many lives. Over the last 15 years there has been a general decline in all the reported Vaccine Preventable Diseases in India but the decline in measles incidence is far below the expected level. In India however, each year about $15 \%$ of the 27 million infants or 4.05 million children remain unimmunized and are potentially at risk of measles infection. Also children less than five years of age contribute to more than $50 \%$ of measles cases indicating low coverage of measles immunization (Rajesh Vaidhya, 2009). Thus measles is still a major public health problem of children in India.

MDG 4 aims to decrease the under-5 mortality rate by 2/3rd by 2015 from 1990 estimates. The proportion of 1 year-old children immunized against measles is the one of the MDG 4 indicators for achieving this lower level. By understanding the efficacy of measles immunization to decrease children deaths, measles immunization coverage has been determined as a marker of measurement to children health services and regular measles immunization coverage was also fixed as an marker of development towards attaining MDG 4 goal.

To achieve elimination by 2020, it requires effective continuous measles surveillance, strengthening of routine immunization by achieving more than 95\% coverage in all districts and nationally, improving case management, implementation of $2^{\text {nd }}$ dose in UIP mandatory at 16 to 24 months throughout India, improve coverage by supplementary immunization activities programs. Thus in all International \& National polices it clearly indicates covering all eligible children by measles vaccination will help to eliminate measles from world.

According to most authors, herd immunity requires more than or equal to $95 \%$ population immunity. However in measles, the population immunity of $80 \%$ only can be achieved by this vaccine efficacy of $85 \%$ and the actual $95 \%$ coverage. Thus in measles, herd immunity is still a long way off (Gregory A, 2012). Epidemiology of measles is of related to population size, density, overcrowding, movement and social behavior. The effects of measles infection predisposes to health problems in later life also.

WHO targets measles next to polio for eradication. The output of the measles immunization program is measured in terms of vaccination coverage and dropout rates. As vaccination coverage rates measures access to immunization services and dropout rates indicates service utilization (Kishore, 2011), it will be worthwhile now to study the prevalence of drop out and factors associated with it. Hence identifying each and every single factor responsible for measles dropout are considered very important to overcome the hurdles in immunization coverage to achieve elimination of measles by 2020 .

\section{Objectives}

The objectives of this study are:

1) To determine the immunization coverage in measles in Kanyakumari district.

2) To identify the factors associated with non coverage of measles immunization.

\section{Materials and Methods}

\section{Study Design and Study Setting:}

This is a Community based cross sectional study. The study was conducted in whole Kanyakumari district in Tamilnadu state. Kanyakumari district has the total population of 18,25,719. It has been further divided into nine Blocks. Each block has one Block Primary Health Centre and two to three additional Primary Health Centres. Thus there are 36 PHCs in rural and 6 Urban Health post in Kanyakumari district. Each primary health centre has four to eight Health Sub Centres (HSC) depending upon their population. Thus Kanyakumari district has totally 267 Rural Health Sub Centers and 22 Urban Health Sectors and together the total of 289 Centers. 
This study has been taken over a period of one year from June 2012 to May 2013. The study population comprised of children in the age group between 12 and 23 completed months (both inclusive) and residing in service limits of the 267 Rural Health Sub Centers and 22 Urban Health Sectors of Kanyakumari District.

\section{Sample Size and Sampling:}

As it is a vaccine coverage study it is proposed to follow $30 \times 7$ cluster sampling method as per WHO norms ${ }^{50}$. Seven eligible children in the age group of 12-23 completed months were studied in each cluster. The total sample size of 210 children in the age group between 12 and 23 completed months (both inclusive) were taken from thirty clusters for this study.

Each health sub centre population has been taken as one cluster. Thirty clusters were taken by cluster sampling technique by population proportionate to size. Cumulative population was calculated and from which each cluster has been identified. For this, a list of all 267 HSCs and 22 UHSs with a population of 18,25,719 is procured. A list of respective and cumulative population of all HSCs and UHSs in done separately in a systematic manner. The cluster interval 60,857 was obtained by dividing the total population by 30 (number of clusters required in the study). By simple random technique the first random number 17515 less than the class interval have been selected.

The HSC or UHS with the cumulative population in which this random number falls was the first cluster. In our study that random number fallen in Kadukkarai rural health sub centre of Thadikarankonam primary health centre and that it has been taken as first cluster. Second cluster was selected by adding the cluster interval of 60,857 to this random number and cumulative population where it was fallen. Then subsequent cluster were taken by adding cluster interval to the selected cumulative population. The procedure was continued subsequently till 30 clusters chosen. Thus following 30 clusters were selected on the basis of cluster sampling technique.

In each cluster, the first household has been chosen randomly and moved in the same direction till seven eligible children were selected. Seven eligible children in the cluster within in the age group of 12-23 completed months who are satisfying with the inclusion \& exclusion criteria were interviewed.

\section{Inclusion Criteria:}

a) Children in the age group between 12 to 23 completed months.

b) Eligible Children having residence in Kanyakumari District.

\section{Exclusive Criteria:}

a) Eligible Children not available at the time/day of data collection.

b) Visitors' child from other place outside Kanyakumari district.

\section{Data Collection and Analysis:}

The Structured pre tested Questionnaire in the vernacular language (translated in child's mother tongue) was used to collect data from the parents/caregivers of the eligible children to collect their socio demographic details, their children's measles immunization status, reason for the dropout if not vaccinated for measles. Dropout is the Child who fails to vaccinate for primary measles vaccination between 9 to 12 months after taking anyone of previous vaccines BCG, OPV/DPT as ascertained from Immunisation Card or History).

Data collection was started by the month of June 2012 after approval from the Institutional Ethical Committee. After getting informed consent from the Parents / Caregivers of the identified study children, pre tested questionnaire were applied. The immunization card or other relevant records on immunization were scrutinized. Data's from two to three clusters have been taken in one month in a sequential manner and all data's from 30 clusters were taken by May 2013 for one year period. 
South American Journal of Public Health

Special Edition May 2016

Data gathered was entered in Microsoft Excel spread sheet and analysis was done by using the SPSS Software Version 18. Simple Proportions, Mean + SD were calculated and Tests of significance like t-test and Chi square test were used. Multiple Logistic Regression was applied to find out the significant factors associated with drop out.

\section{Results}

\section{General Characteristics:}

The age of the study population $(\mathrm{N}=120)$ was from 12 to 23 completed months. Mean age was 18.1 months with Standard Deviation of 3.1 months. Majority 69 (32.9\%) of them were in 18-20 months age group followed by 15-17 months (26.2\%) and then 21-23 months (24.8\%). Only 34 (16.2\%) were in 12-14 age group category. In the study population female children constituted 109 ( 51.9\%) which is little higher than male children 101 (48.1\%). Of the total 210 Children, 175 (83.3\%) Children were residing in the Rural area and other 35 (16.7\%) were residing in Urban area.

Out of total 210 children in the study population, more than $50 \%$ children were belonging to Christians 111 (52.8\%) which was followed by Hindus 85 (40.47\%) and then Muslims 14 (6.7\%). Most of the children belongs to Nuclear family (113 - 53.8\%) followed by Three Generation family (18 - 37.6\%) and Joint or Extended family (18 - 8.6\%).

In the study population, just more than half of them majority of them were at second order (51.9\%), followed by first order which contituted $46.7 \%$ an donly $1.4 \%$ were in the third birth order. The socio economic status of the children in the study population were classified according to the modified kuppuswamy's SES scale. $45.7 \%$ of the children were belonging to Upper middle class followed by Lower middle class of $34.3 \%$ and Upper lower class $16.7 \%$. Children belonging to Upper class constitutes the lowest by 3.3\%. None of the children belonging to Lower class.

\section{Measles Immunisation Coverage}

Table 1: Measles vaccination

\begin{tabular}{|l|c|c|}
\hline Measles Vaccination & Number & Percentage \\
\hline 1. Yes & 171 & 81.4 \\
\hline 2. No & 39 & 18.6 \\
\hline Total & 210 & 100 \\
\hline
\end{tabular}

Out of 210 children, 171 children (81.4\%) were immunized for measles vaccination. But 39 children (18.6\%) were immunized with BCG, one of three OPV\& DPT doses but fail to vaccinate for Measles immunization. Hence drop out for Measles immunization was $18.6 \%$.

Out of 210 children, 178 (84.8\%) had immunization card and 15.2\% did not have the card.

Table 2: Age at Vaccination

\begin{tabular}{|l|c|c|c|c|c|}
\hline & $\mathrm{N}$ & Minimum & Maximum & Mean & $\begin{array}{c}\text { Std. } \\
\text { Deviation }\end{array}$ \\
\cline { 2 - 5 } $\begin{array}{l}\text { Age at Vaccination } \\
\text { (in Days) }\end{array}$ & 171 & 248 & 358 & 293.94 & 26.012 \\
\hline
\end{tabular}


Table 3: Place of Vaccination

\begin{tabular}{|l|l|l|}
\hline Place of Vaccination & Number & Percentage \\
\hline 1. Private Hospitals & 60 & 35.1 \\
\hline 2. GH & 33 & 19.3 \\
\hline 3. PHC & 22 & 12.9 \\
\hline 4. HSC & 50 & 29.2 \\
\hline 5. Outreach & 1 & 0.6 \\
\hline 6. Maternity Centre & 5 & 2.9 \\
\hline Total & 171 & 100 \\
\hline
\end{tabular}

Out of 171 children who immunized for measles vaccination, $64.9 \%$ vaccinated in Government facility and only $35.1 \%$ of children vaccinated in private setup. The utilization of immunization services in Govt health care facilities were in the following order as: HSC (29.2\%), GH(19.3\%), PHC(12.9\%), Maternity Centre(2.9\%) and Out reach camps (0.6\%).

Out of 171 children vaccinated, 100 (58.5\%) children were taken by parents and 71 (41.5\%) children were taken by relatives to the immunisation site.

\section{Factors associated with Drop Outs}

Table 4: Reasons given by the Parents / Caregivers

\begin{tabular}{|c|c|c|c|}
\hline S. No & Reasons for Non Immunization & Number & Percentage \\
\hline 1 & $\begin{array}{l}\text { Was not aware of the Vaccination } \\
\text { Schedule }\end{array}$ & 7 & 17.9 \\
\hline 2 & Time and place not known & 2 & 5.1 \\
\hline 3 & $\begin{array}{l}\text { Day \& Time of vaccination is not suitable } \\
\text { for us }\end{array}$ & 1 & 2.6 \\
\hline 4 & $\begin{array}{l}\text { Place of Vaccination is too for and lack of } \\
\text { transportation }\end{array}$ & 2 & 5.1 \\
\hline 5 & Baby was sick at the time of Immunization & 4 & 10.3 \\
\hline 6 & $\begin{array}{l}\text { Fear of adverse events following } \\
\text { immunization }\end{array}$ & 4 & 10.3 \\
\hline 7 & Has already been infected with measles & 4 & 10.3 \\
\hline 8 & $\begin{array}{l}\text { Have knowledge } \& \text { attitude but forgot to } \\
\text { vaccinate due to longer time gap between } \\
\text { DPT } 3^{\text {rd }} \text { dose and measles vaccination }\end{array}$ & 10 & 25.6 \\
\hline 9 & Ignorance & 5 & 12.8 \\
\hline 10 & Haven’t given due to Religious factor & 0 & 0.0 \\
\hline \multicolumn{2}{|l|}{ Total } & 39 & 100 \\
\hline
\end{tabular}

Among reasons for non immunization of measles vaccination, forgetfulness due to longer timegap between OPV/DPT $3^{\text {rd }}$ Dose and Measles vaccine was the most common factor for drop out constituting 25.6\%. The next common factor was unawareness of vaccination schedule which constitutes $17.9 \%$. The third common factor was ignorance for measles vaccination inrespect of lack of knowledge, unawareness, uneducated, uninformed which constitutes $12.8 \%$. Then the Child sickness at the time of vaccine, Fear of Adverse Events 
South American Journal of Public Health

Special Edition May 2016

Following immunization and Previous attack by measles disease are the three factors contributing equal proportion (10.3\%).

Table 5: Socio Demographic Factors associated with Drop Outs ( $\mathrm{T}$ - Test)

\begin{tabular}{|l|l|l|l|l|l|l|}
\hline \multirow{2}{*}{ Factors } & \multicolumn{2}{|c|}{ DROP OUTS } & \multicolumn{2}{l|}{ VACCINATED } & \multirow{2}{*}{ F-Value } & \multirow{2}{*}{ p-Value } \\
\cline { 2 - 6 } & Mean & SD & Mean & SD & & \\
\hline Age (Days) & 573.9 & 92.9 & 557.4 & 85.42 & 1.099 & 0.296 \\
\hline Father's Age (Yrs) & 32.97 & 3.64 & 32.67 & 4.11 & 0.178 & 0.673 \\
\hline Mother's Age (Yrs) & 27.31 & 2.91 & 27.67 & 3.89 & 0.304 & 0.582 \\
\hline Total Family Income (Rs.) & 8487 & 3640 & 17026 & 33652 & 2.495 & 0.116 \\
\hline Total Family Members & 4.77 & 1.29 & 4.54 & 1.19 & 1.106 & 0.294 \\
\hline Distance (Km.) & 4.21 & 2.33 & 3.31 & 2.39 & 4.538 & $\mathbf{0 . 0 3 4}$ \\
\hline
\end{tabular}

The above table 5 shows the difference between the mean values of Drop outs and Vaccinated Children respectively. The mean Age of children, Father's Age, Total Income, Total family Members and Distance to the nearby government health facility of Drop outs were high as compared the vaccinated children. But among them Distance was the only statistically significant factor.

The mean Mother's Age, and Total family Income of Drop outs were lower than the Vaccinated children. But these were not statistically significant.

Table 6: Socio Demographic Factors associated with Drop Outs (Chi2 Test)

\begin{tabular}{|c|c|c|c|c|c|c|c|}
\hline \multirow{2}{*}{ Factors } & \multirow{2}{*}{ Category } & \multirow{2}{*}{$\mathbf{N}$} & \multicolumn{2}{|l|}{ DROP OUT } & \multirow{2}{*}{$\begin{array}{l}\text { OR }(95 \% \\
\text { CI) }\end{array}$} & \multirow{2}{*}{$\begin{array}{l}\mathrm{Chi}^{2} \\
\text { Value }\end{array}$} & \multirow{2}{*}{$\begin{array}{l}\text { p- } \\
\text { Value }\end{array}$} \\
\hline & & & Yes & No & & & \\
\hline \multirow{2}{*}{$\begin{array}{l}\text { Area of } \\
\text { Residence }\end{array}$} & Rural & 175 & 37 (21.1\%) & 138 (78.9\%) & \multirow{2}{*}{$\begin{array}{c}4.42 \\
(1.01- \\
19.29)\end{array}$} & \multirow{2}{*}{4.591} & \multirow{2}{*}{0.032} \\
\hline & Urban & 35 & $2(5.7 \%)$ & 33 (94.3\%) & & & \\
\hline \multirow{2}{*}{ Place of Birth } & Govt. & 64 & 13 (20.3\%) & 51 (79.7\%) & \multirow{2}{*}{$\begin{array}{c}1.18 \\
(0.56-2.47)\end{array}$} & \multirow{2}{*}{0.185} & \multirow{2}{*}{0.668} \\
\hline & Private & 146 & $26(17.8 \%)$ & $120(82.2 \%)$ & & & \\
\hline \multirow{2}{*}{ Sex } & Male & 101 & 15 (14.9\%) & 86 (85.1\%) & \multirow{2}{*}{$\begin{array}{c}0.62 \\
(0.30-1.26)\end{array}$} & \multirow{2}{*}{1.781} & \multirow{2}{*}{0.182} \\
\hline & Female & 109 & 24 (22.0\%) & 85 (78.0\%) & & & \\
\hline
\end{tabular}


South American Journal of Public Health

Special Edition May 2016

\begin{tabular}{|c|c|c|c|c|c|c|c|}
\hline \multirow{2}{*}{$\begin{array}{l}\text { Parents' } \\
\text { Marital Status }\end{array}$} & Married & 202 & 36 (17.8\%) & 166 (82.2\%) & \multirow{2}{*}{$\begin{array}{c}0.36 \\
(0.08-1.58)\end{array}$} & \multirow{2}{*}{1.970} & \multirow{2}{*}{0.160} \\
\hline & Others & 8 & 3 (37.5\%) & $5(62.5 \%)$ & & & \\
\hline \multirow{2}{*}{$\begin{array}{l}\text { Mothers' } \\
\text { current } \\
\text { Pregnancy } \\
\text { Status }\end{array}$} & Pregnant & 30 & $6(20.0 \%)$ & 24 (80.0\%) & \multirow{2}{*}{$\begin{array}{c}1.11 \\
(0.42-2.94)\end{array}$} & \multirow{2}{*}{0.047} & \multirow{2}{*}{0.828} \\
\hline & $\begin{array}{l}\text { Non } \\
\text { Pregnant }\end{array}$ & 180 & 33 (18.3\%) & 147 (81.7\%) & & & \\
\hline \multirow{2}{*}{$\begin{array}{l}\text { Immunisation } \\
\text { Card } \\
\text { available }\end{array}$} & No & 32 & 17 (53.1\%) & 15 (46.9\%) & \multirow{2}{*}{$\begin{array}{c}8.33 \\
(3.57- \\
20.08)\end{array}$} & \multirow{2}{*}{29.81} & \multirow{2}{*}{0.000} \\
\hline & Yes & 178 & $22(12.4 \%)$ & 156 (87.6\%) & & & \\
\hline
\end{tabular}

The above table 6 shows, Rural Children are at 4.42 times risk for Dropping out as compared to urban children and this is statistically significant (p-Value 0.032). In the same manner, Children not having Immunization in hand are at 8.33 time risk for dropping out as compared to children having the Immunisation card with them. This also statistically significant as the $\mathrm{p}-$ Value is $<0.001$.

Regarding the other variables, Children with Place of Birth at Government facility, Female Gender, Parents' Marital status Other than married and living together, Mothers currently pregnant were at having higher proportion of Drop outs as compared to their respective counter parts, but these are not statistically significant.

After Multiple Logistic Regression Analysis, Area of Residence, Marital Status of the parents, Total Income, Distance and the Availability of Immunisation card are the significant factors associated with Dropouts.

\section{Discussion}

There were totally 210 children eligible children with the residence at Kanyakumari district and in between the age group of 12 to 23 completed months. Out of this 120 children, female children constitute little higher (109 - 51.9\%) than male children (101 - 48.1\%). 175 (83.3\%) Children were residing in the Rural area and other 35 (16.7\%) were residing in Urban area.

Out of 210 children, 171 children (81.4\%) were immunized for measles. But 39 children (18.6\%) were immunized with BCG, OPV\& DPT doses but failed to vaccinate for Measles immunization. Hence drop out for Measles immunization was $18.6 \%$. This was ascertained from Immunisation Card or History. Out of 210 children, 178 (84.8\%) had immunization card and 32 (15.2\%) do not have card.

This $81.4 \%$ measles coverage is lower than the Report of an Immunisation Coverage Survey (Pushpa Narayan, 2011) in Tamilnadu by Makkal Nalavazhvu Iyakkam \& CHAD, CMC Vellore in 2011 with coverage of $87.1 \%$ at Kanyakumari district. But it is comparable with UNICEF's 'The Coverage Evaluation Survey 2009' which states measles vaccination in India was $80 \%$ with $20 \%$ drop out (UNICEF, 2009) and also it is more than coverage of $69 \%$ by DLHS-3 in 2007-2008.

Bhagyalaxmi A et al conducted a Study of incidence of measles and vaccination coverage in Ahmedabad urban slums (Bhagyalaxmi A, 2007) and found Measles vaccination coverage in December 2004 was only 59.88\% which is much lower than our measles coverage of $81.4 \%$. Vaccination coverage study in slums of Surat city by SJ Kadapia et al concluded the vaccination coverage in the $12-23$ months age group was $49.8 \%$ which was very lower compared to our study coverage of $81.4 \%$ (VK Desai, 2003). This is higher than Niyi awofeso et al study on age-appropriate vaccination against Measles and DPT-3 in India which was found only 72.4\% (Niyi Awofeso, 2013). 
South American Journal of Public Health

Special Edition May 2016

Of the 171 who had immunised for measles, the age at which they had immunised ranges from minimum 248 days to maxium 358 days with mean age of 294 days and standard deviation of 26 days. If the child had vaccinated but after 12 completed months it was considered as drop out.

Out of 171 children who immunized for measles vaccination, $64.9 \%$ vaccinate in govt set up and only $35.1 \%$ of children vaccinate in private set up. It was also observed that the utilization of immunization services in govt health care facilities were in the following order as HSC (29.2\%), GH(19.3\%), PHC(12.9\%), Maternity centre (2.9\%), Out reach camps (0.6\%). This correlates with Niyi awofeso et al study in place of vaccination where HSC were preferred the highest among the govt health care facilities (Niyi Awofeso, 2013).

\section{Factors associated with Drop Outs}

Among reasons for non immunization of measles vaccination, forgetfulness due to longer timegap between OPV/DPT $3^{\text {rd }}$ Dose and Measles vaccine was the most common factor for drop out constituting $25.6 \%$. The next common factor was unawareness of vaccination schedule which constitutes $17.9 \%$. The third common factor was ignorance for measles vaccination inrespect of lack of knowledge, unawareness, uneducated, uninformed which constitutes $12.8 \%$. Then the Child sickness at the time of vaccine, Fear of Adverse Events Following immunization and Previous attack by measles disease are the three factors contributing equal proportion (10.3\%); Not knowing time \& place of vaccination constitutes $5.1 \%$ of drop out and Not knowing day \& time of vaccination, long distance for the place of vaccination, no faith in vaccination constitutes $2.6 \%$ each.

In the study of measles incidence and vaccination coverage in slums of Surat city by SJ Kapadia et al concluded the commonest reason for non-vaccination was ignorance of parents about the seriousness of the disease and the need of vaccination which is correlating with our study findings on ignorance factor (12.8\%) for drop out (VK Desai, 2003).

In a study conducted in brigham young university, Provo, USA on Parental Factors in Delayed Childhood Immunization was confused about the immunization schedule which correlated with our finding on lack of immunization schedule (17.9\%.) is a factor for non immunization (Karlen EL, 2009).

Hussen Mohammed \& Dire Dawa , Public Health Faculty, Department of Epidemiology, Jimma University, Eastern Ethiopia conducted a study on Assessment of Child Immunization Coverage and Associated Factors Unaware the need of immunization, didn't return for 2nd and 3rd dose because of fear of side reaction, lack of information on place and/or time of immunization and wrong perception about contraindication were statistical significant factors children (Hussen Mohammed, 2013) which is correlating with our study factors like Fear of Adverse Events Following immunization,previous attack by measles knowing day \& time of vaccination, long distance for the place of vaccination as important factors for drop out.

S. Yadav et al conducted a study on Evaluation of Immunization Coverage in Urban Slums of Jamnagar City and found Ignorance, Inconvenience, Short supply, schedule not as planned, Problem of relation between health worker \& community are the factors associated with drop out and Our study is strongly associated with these findings for drop out (Singh P, 2000).

The study on factors influencing immunization coverage in Mathare Valley, Nairobi observed that the immunization status of the study population is significantly influenced by ignorance of need for immunizations and of return dates, fear of adverse events following immunization which is correlating with our study findings on AEFI \& ignorance as factors associated with drop out (Owino LO, 2009).

A study in Papua New Guinea on factors affecting information to mothers on when to start immunization and how often the child should be immunized were key factors in determining immunization status is correlated with our study finding on maternal knowledge, unawareness, uneducated, uninformed which constitutes $12.8 \%$ for drop out (Freeman PA, 1992). 
The ' $\mathrm{t}$ ' test shows no significant difference between vaccinated children drop out children mean in the following demographical factors like age, father's age, mother's age, total family income and total family members. But the Distance to nearest govt. facility is statistically significant (p-Value 0.034) different between vaccinated with drop out. Higher the distance of health facility the chance of the child to drop out also will be more.

Regarding socio-demographical factors associated with drop out, when Area of Residence and Non Immunization were analyzed, it shows Rural children are 4.42 times likely to drop out as compared to urban children $\left(\mathrm{Chi}^{2}-4.591\right.$, DF - 1, p-Value - 0.032 Statistically Significant). This is consistent with the study done by Rup Kumar Phukan et al on factors associated with Immunization Coverage of Children in Assam, India which found the children from urban areas significant more immunization coverage than rural (Rup Kumar P, 2009).

Regarding sex of child, female children were more likely drop out, but as this wass not statistically significant. A study on "Assessment of immunization in the slums of Surat by 15 clusters multi indicators cluster survey technique” by Dr. Rashmi Sharma, Vikas Desai, Abhay Kavishvar in 2009, found that female children were more disadvantaged in terms of vaccination which is correlating with our study where females were more drop out than males (VK Desai, 2009).

Presence of immunization card was the statistically significant factor with drop out. Children without immunization card were 8.33 times more risk to be dropped out than with those who had the card $(\mathrm{p}<0.001)$. This is supported by Abhishek Kumar and S.K. Mohanty who conducted a study in 2009 in three states on the role of the presence of Immunisation Card in the house and observed that the absence of Immunisation Card as a factor associated with slow progress in Childhood Immunisation in India (Abhishek Kumar, 2009).

Multiple Logistic Regression analysis of the above significant factors shows that Area of Residence, Marital Status of the parents, Total Family Income, Distance and the Availability of Immunisation Card are the significant factors associated with Drop outs.

\section{Conclusion}

1. The coverage for measles immunization in Kanyakumari District is $81.4 \%$. Hence the prevalence of dropout in Measles vaccination in Kanyakumari District is $18.6 \%$.

2. Among reasons for non immunization of measles vaccination, forgetfulness due to longer timegap between OPV/DPT $3^{\text {rd }}$ Dose and Measles vaccine was the most common factor for drop out constituting to $25.6 \%$.

3. Factors like Area of Residence, Marital Status of the parents, Total Family Income, Distance to the nearby government health facility and the Availability of Immunisation Card were the statistically significant factors associated with Drop outs.

\section{Recommendations}

1. Long gap between $3^{\text {rd }}$ dose DPT and Measles should be engaged with iron or vitamin syrups monthly to child, so that health care providers shall have close contact with children and mothers to prevent this drop out.

2. Since longer the distance of the Government facility from the child residence contributing significantly to drop out, Outreach measles vaccination camps can be arranged by Mobile clinics at far distance, uncovered areas and hilly areas.

3. Immunization card should be given to all children from birth and missed cards to be replaced every now and then during further visits to avoid forgetfulness.

4. In the field level, the beneficiaries of measles vaccination should be monitored and supervised by Sector Health Nurses periodically to identify drop out by VHN.

5. Awareness about measles vaccination at 9 months should be done periodically through all possible media by public health department till it is eliminated from India. 
South American Journal of Public Health

Special Edition May 2016

\section{References}

[1.] Abhishek Kumar, S.K. Mohanty. (2009). Understanding the Factors Associated with slow Progress in Childhood Immunisation in India. Paper Submitted in XXVI IUSSP International Population Conference in Marrakech, Morocco. 2009.

[2.] Akhalesh Kumar Shakya, Vibha Shukla, Harjeet Singh Maan, Tapan N Dhole. (2012). Identification of different lineages of measles virus strains circulating in Uttar Pradesh, No rth India. Virology Journal, 9:237 DOI:10.1186/1743-422X-9-237.

[3.] Bhagyalaxmi A, Kedia G, Rawal VS. (2007). Study of incidence of measles and vaccination coverage in Ahmedabad urban slums. Indian J Public Health 2007;51(1):52-53.

[4.] DLHS 2007-08. District Level household and Facility Survey 2007-08. Fact Sheets India. Ministry of Health and Damily Welfare, Nirman Bhavan, New Delhi 110011.

[5.] Freeman PA, Thomason JA, Bukenya GB, (1992). Factors affecting the use of immunization among urban settlement dwellers in Papua New Guinea. PNG Med J. 1992 Sep; 35(3) : 179-85.

[6.] Gregory A. Poland, Robert M Jacobson. (2012). The Re-Emergence of Measles in Developed Countries: Time to Develop the Next-Generation Measles Vaccines? Vaccine Jan 5, 2012; 30(2): 103104.

[7.] Hussen Mohammed, Alemayehu Atomsa. (2013). Assessment of Child Immunization Coverage and Associated Factors in Oromia Regional State, Eastern Ethiopia. Science, Technology and Arts Research Journal .Jan-Mar 2013,2(1): 36-41.

[8.] Kishore J. (2011). Reproductive and Child Health Program -II. In: J. Kishore (Editor), National Health Programs of India, 9th Edition. Century Publishers, New Delhi, 2011: 155-160.

[9.] National Rural health Mission 2014. Disease Alerts /Outbreaks Reported and Responded to by the States / UTs through IDSP 22nd week 2014. Ministry of Health and Family Welfare, Nirman Bhavan, New Delhi -110011. Available at: http://www.idsp.nic.in/idsp/IDSP/rcntobrk.pdf Accessed on 02 June 2014.

[10.] Niyi Awofeso, Anu Rammohan, Kazi Iqbal. (2013). Age-appropriate vaccination against measles and DPT-3 in India - closing the gaps. BMC Public Health, 13:358 DOI:10.1186/1471-2458-13-358.

[11.] Owino LO, Irimu G, Olenja J, Meme JS. (2009). Factors influencing immunization coverage in Mathare Valley, Nairobi, East Afr Med J. 2009 Jul; 86(7) 322-9.

[12.] Pushpa Narayan. (2011). TN moms to get cash for vaccines. The Times of India (Chennai Edition), Aug 1, 2011. Availabel at http://timesofindia.indiatimes.com/city/chennai/TN-moms-to-getcash-for-vaccines/articleshow/9438314.cms Accessed on 20 Feb 2014.

[13.] Rajesh Vaidhya. (2009). Measles. In: RajVir Bhalwar, Chief Editor, Text Book of Public Health and Community Medicine, First Edition, New Delhi, AFMC, 2009: 1089-92.

[14.] Rup Kumar Phukan, Manash Pratim Barman, Jagadish Mahanta. (2009). Factors Associated with Immunization coverage of children in Assam, India : Over the first year of life. Journal of Tropical Pediatrics. Volume, 55, Issue 4 : Pp. 249 - 252.

[15.] Singh P, Yadav R.J. (2000). Immunization status of children of India. Indian Pediatrics; 37: 1194-1199.

[16.] Surender N Gupta, Naveen Gupta. (2009). Two highly immunized hilly areas versus double measles outbreak investigations in district Kangra, Himachal Pradesh, India, in 2006. Public Health Research; 1(1): 14-20.

[17.] UNICEF - Coverage Evaluation Survey 2009: National Fact Sheet. Ministry of Health and Family Welfare, Nirman Bhavan, New Delhi - 110011.

[18.] VK Desai, SJ Kapadia, Pradeep Kumar, Siddharth Nirupam. (2003). Study of Measles Incidence and Vaccination Coverage in Slums of Surat City. Indian Journal of Community Medicine Vol. XXVIII, No.1, Jan.-Mar., 2003. 10-14.

[19.] World Health Organization. (2014). Fact Sheet - Measles, Fact sheet N²86, Updated February 2014. Available at: http://who.int/mediacentre/factsheets/fs286/en/ accessed on 23 March 2015. 